\title{
LA MÚSICA SACRA INSTRUMENTAL DE ÓRGANO Y EL GREGORIANO: FRANCISCO CORREA DE ARAUXO (1584-1654) Y LA SALVE REGINA SOLEMNE
}

\author{
POR
}

\section{RAMÓN DE LA CAḾPA CARMONA}

Abraham MarTíneZ FerNáNdez

JESÚS SAMPEDRO MÁRQUEZ

\section{Resumen}

Este estudio aborda la introducción de la música y las composiciones de órgano en el culto católico en la época de la Contrarreforma, descrito por medio de uno de los músicos espaffoles más importantes del Barroco, Francisco Correa del Arauxo, sirviéndose del análisis de la Salve Regina del citado compositor.

\section{ABSTRACT}

This study approaches on the music introduction and the organ compositions in the catholic cult in the Counter Reformation Age, described by means of one of the more important Spanish musicians in the Baroque time, Francisco Correa de Arauxo, through the analysis of his Salve Regina.

\section{LA MÚSICA SACRA INSTRUMENTAL}

El concepto de música sacra tiene muchas definiciones. Nosotros partimos de un concepto objetivo: es aquella que se compone para expresar las vivencias religiosas del hombre. Es algo sustancial a la expresión ritual del hecho reli-

Actas del I Congreso de Historia de la Iglesia y el Mundo Hispánico Hispania Sacra, $52(2000)$ 
gioso, pues, en palabras del Papa San Pío X, «en cualquier época y entre cualquiera clase de gentes, hasta las menos civilizadas, toda vez que se ha organizado un culto público, la música tuvo allí su papel, más o menos importante según el mayor o menor desarrollo de la organización litúrgica» ${ }^{1}$. Como señala el Vaticano II, su valor depende de la adecuación música-culto: «La música sacra, por consiguiente, será tanto más santa cuanto más íntimamente esté unida a la acción litúrgica, ya sea expresando con mayor delicadeza la oración o fomentando la unanimidad, ya sea revistiendo de mayor solemnidad los ritos sagrados $)^{2}$. Muy dificil es de evaluar algo tan abstracto, y los criterios están en buena medida sometidos a historicidad; en todo caso, como afirmó Pablo VI, «si no posee a la vez el sentido de la oración, de la dignidad y de la belleza, la música -instrumental y vocal-, ella misma, se cierra la entrada en la esfera de los sagrado y de lo religioso ${ }^{3}$.

La Iglesia no podia dejar de utilizar para su misión apostólica y santificadora el potencial de la música como hace con el resto de las manifestaciones artísticas. Magistralmente lo resume el Papa Juan Pablo II, cuyas hermosas palabras no nos resistimos a transcribir: «La música tiene capacidades altísimas de expresar las riquezas de toda cultura. No sólo esto: sino que por su naturaleza se puede hacer resonar armonías interiores, despierta intensas y profundas emociones, ejerce un poderoso influjo con su encanto. Tanto si exalta la palabra del hombre como si da forma melódica a la Palabra que Dios ha revelado a los hombres, como si difunde sin palabras, la música, como voz del corazón, suscita ideales de belleza, la aspiración a una perfecta armonía que no turban pasiones humanas y el sueño de una comunión universal. Por su trascendencia, la música es también expresión de libertad: escapa a todo poder y puede convertirse en refugio de extrema independencia del espíritu donde ella canta, aun cuando todo parezca envilecer o coaccionar al hombre. Por tanto la música tiene, en sí misma, valores esenciales que interesan a todo hombre" ${ }^{4}$.

Además, el carácter celebrativo del culto cristiano -el cristianismo es la religión del evangelio, la «buena nueva»-exige la música" $a^{5}$ no hay fiesta sin música ${ }^{6}$, que brota espontáneamente como expresión de los sentimientos desbordados. La Liturgia, además, anticipa escatológicamente la plenitud gozosa de la realidad salvífica de Cristo: «En la liturgia terrena pregustamos y toma-

\footnotetext{
I Motu proprio Tra le sollecitudini, 22-XI-1903, en Garrido BonAÑo, 1965, t. I, p. 546.

2 Vaticano II, Constitución de Sagrada Liturgia Sacrosanctum Concilium, 1963, n. ${ }^{\circ} 112$. En: ALDAZABAL, 1988, p. 7.

${ }^{3}$ Pablo VI a la Asociación de Santa Cecilia, 1968. En: Aldazabal, 1988, p. 27.

4 A monsefior Domenico Bartolucci, 6-VIII-1985, n. ${ }^{\circ}$ 2. En: ALDAZÁBAL, 1988, pp. $45 \mathrm{~s}$.

5 UNiversa LaUs, La música en las liturgias cristianas, 1980, I. 1. En: AldazABal, 1988, p. 53.
} 
mos parte en aquella liturgia celestial que se celebra en la santa ciudad de Jerusalén, hacia la cual nos dirigimos como peregrinos y donde Cristo está sentado como ministro del santuario y del tabernáculo verdadero (cf. Apoc. 21, 2; Col. 3,$1 ; H e b .8,2$ ); cantamos al Señor el himno de gloria con todo el ejército celestial»?

En este sentido, la preocupación de las comunidades cristianas por la música es históricamente comprobable: «como es sabido, la Iglesia ha cultivado y favorecido siempre la música, en cuanto testimonio de la riqueza vital de una comunidad; más aún, ha sido siempre mecenas de ella, bien consciente de su importancia espiritual, cultural y social» ${ }^{8}$. Hasta tal punto se considera importante la música en las celebraciones, que se les reconoce un auténtico ministerio litúrgico a los músicos, pues éstos «cuando están encargados por la autoridad eclesiástica competente de servir el altar o de ejecutar la música sagrada, si realizan esta tarea del modo y forma establecido por las rúbricas, ejercen un servicio ministerial directo, pero delegado" ${ }^{9}$. Pues (algunos miembros de la comunidad son reconocidos por las dotes especiales que muestran en dirigir la alabanza y la acción de gracias musicales de las asambleas cristianas; son los músicos pastorales, cuyo ministerio es especialmente apreciado por la Iglesia) ${ }^{10}$.

La música sagrada se puede dividir en dos grandes apartados: música vocal, en que se musicalizan himnos y plegarias, y música instrumental, que ambienta las celebraciones y acompaña diversos rituales y silencios meditativos. También pueden combinarse ambas en fecunda simbiosis, en cuyo caso la primera de las modalidades será la que lleve la voz cantante. Mientras que el canto de los textos eucológicos es algo inherente a la Liturgia, que surge espontáneamente, la introducción de la música instrumental, en cambio, presenta un estadio más avanzado de desarrollo en la expresión ritual del hecho religioso.

La Iglesia dice al respecto: (los instrumentos musicales pueden ser de gran utilidad en las celebraciones sagradas, ya acompañen el canto, ya intervengan solos (...). Todo instrumento admitido en el culto se utilizará de forma que responda a las exigencias de la acción litúrgica, sirva a la belleza del culto y a la edificación de los fieles» ${ }^{11}$. Como se reconoce explícitamente, incluso «en cier-

\footnotetext{
6 Vid. Taule, A.: «Música y clima festivom. En: AldazÁBal, 1985, pp. 14 ss.

7 VATiCano II, Constitución de Sagrada Liturgia Sacrosanctum Concilium, n. ${ }^{\circ} 8$.

8 Ibidem, n. ${ }^{\circ} 5$, p. 47.

9 Sagrada Congregación de Ritos, Instrucción de 3-IX-1958, n. 93 c. En: Manzarraga, 1965, p. 17.

10 Comasión de Obispos para la LituRgia de U. S. A., La música litúrgica hoy, 1982, n. ${ }^{\circ} 63$. En: ALDAZÁBAL, 1988, p. 82.

" SAGRADA CONGREGación de Ritos, Instrucción Musicam Sacram sobre la mísica en la Sagrada Liturgia, 1967, n. ${ }^{\circ}$ 62. En: AldAZÁBAL, 1988, p. 23.
} 
tos casos el acto musical constituye un rito en sí mismo: sonido de campanas, música de meditación. En ciertos casos se integra al rito: procesión o acción sin canto. Empleada así, la música puede destacar el aspecto de acontecimiento del rito, dar una cierta calidad a la duración, expresar la fiesta, dar soporte a la contemplación. Finalmente, ella misma puede convertirse en gesto de plegaria» ${ }^{12}$.

\section{EL ORGANO, INSTRUMENTO REY}

Dentro de la música sagrada instrumental, la que más se ha identificado con la esfera de lo religioso en nuestra civilización occidental es la organística, hasta tal punto que la evolución de este instrumento, el órgano ${ }^{13}$, se considera fruto de su uso litúrgico ${ }^{14}$. Quizá pasó a Occidente por medio de Espafaa, donde ya existía a mediados del siglo V; San Isidoro de Sevilla lo menciona en su tratado de música ${ }^{15}$. Su tradición en la Iglesia es larga: se afirma que el Papa San Vitaliano (657-672) lo introdujo en las iglesias por el $660^{16}$. En la Península Ibérica se documenta su existencia en el 972 en la iglesia del Monasterio de Sant Benet de Bages ${ }^{17}$; se va generalizando su uso en el interior de los templos entre los siglos IX al XII, en torno al cual acaba por imponerse.

El Vaticano II, conforme a la tradición, reconoce la importancia de este instrumento en la liturgia occidental: «Téngase en gran estima en la Iglesia Latina el órgano de tubos como instrumento musical tradicional, cuyo sonido puede aportar un esplendor notable a las ceremonias eclesiásticas y levantar poderosamente las almas hacia Dios y hacia las realidades celestiales» ${ }^{18}$. Poco antes ya se había señalado: «Cuando [los organistas] se sientan al órgano durante las

\footnotetext{
12 UNIVERSA LAUS, La música en las liturgias cristianas, 1980, 1. 6. 4. En: ALDAZÁBAL, 1988, p. 58.

13 Su nombre procede del gr. órganon, «instrumenton, y, en particular «instrumento de música». Se le aplica posteriormente al órgano de tubos, aerófono de fuelle tocado por medio de teclados, por considerarse instrumento por antonomasia, por la riqueza de sus sonidos y registros. Vid. MANZARRAGA, 1965 , p. 31 .

14 Por ejemplo: «El cristianismo ha inventado el órgano y ha dado suspiros el mismo bronce» (Chateaubriand, Génie du Christianisme, 30 parte, I. 1, cap. I; en: ManzARRAGa 1965, p. 32). «El genio cristiano ha inventado como único acompafiamiento, que parece ser necesario, el noble instrumento que en todas y en cada una de nuestras iglesias ocupa su puesto incontestable: el órgano, que reúne en sí la más grande ingeniosidad junto con una variedad extraordinaria de expresión sonora” (Richard WAGNER, en: ibldem).

is Vid. Fernández DE LA Cuesta, 1983, pp. 347 ss.

16 Vid. GOMA, 1945, t. I, p. 442.

17 Vid. FERnÁNDEZ DE LA CUESTA, ibidem, n. ${ }^{\circ} 4$.

18 PaBlo VI, Constitución de Sagrada Liturgia Sacrosancrum Concilium, en: Acta Apostolicae Sedis, t. LVI, 1964, pp. 97 ss., n. ${ }^{\circ} 120$.
} 
funciones sagradas, deben ser conscientes de la parte activa que desempeñan para gloria de Dios y santificación de los fieles» ${ }^{19}$. Su misión como solista queda por tanto especificada en: ambientación festiva, acompañamiento del rito y caracterización de los tiempos y las festividades de la Liturgia (incluso con su ausencia, como veremos a continuación).

Su lugar en el culto queda perfectamente delimitada por las indicaciones y prescripciones anotadas a continuación. «En los ejercicios piadosos serán muy útiles sobre todo los salmos, las obras de música sagrada del tesoro antiguo y moderno, los cantos religiosos populares así como el sonido del órgano y de otros instrumentos apropiados» ${ }^{20}$. En cuanto a la Eucaristía: «en las misas cantadas o leídas se puede utilizar el órgano, o cualquier otro instrumento admitido para acompañar el canto del coro y del pueblo. Se puede tocar en solo antes de la llegada del sacerdote al altar, en el ofertorio, durante la comunión y al final de la misma»"21. «El sonido solo de estos instrumentos no está autorizado durante los tiempos de Adviento y Cuaresma, durante el Triduo Sacro y en los oficios o misas de difuntos" ${ }^{22}$.

Mientras que en el ofertorio y comunión sigue o suple al canto, el crear una atmósfera adecuada antes de la celebración y solemnizar la disolución de la asamblea, momento en que, por tanto, no procede el canto que es una expresión comunitaria, es su ámbito más propio: «Será oportuno que el órgano sea utilizado ampliamente para preparar y concluir las celebraciones» ${ }^{23}$.

\section{EL GREGORIANO, MÚSICA SAGRADA POR EXCELENCIA DE LA CIVLIZACIÓN OCCIDENTAL}

La música gregoriana se considera en nuestra cultura la música sacra por excelencia. Así, en la Sacrosanctum Concilium se declara: «La Iglesia reconoce el canto gregoriano como el propio de la liturgia romana; en igualdad de circunstancias, por tanto, hay que darle el primer lugar en las acciones litúrgicas ${ }^{24}$. A esto se suma la ventaja de poseer completo el repertorio litúrgico en la

19 Sagrada Congregación de Rutos, Instrucción de 3-IX-1958, n. ${ }^{\circ}$ 65. En: Manzárraga, 1965 , p. 17.

20 SAGrada CONGREGACión DE RrTos, Instrucción Musticam Sacram sobre la música en la Sagrada Liturgia, 1967, n..$^{\circ}$ 46. En: ALDAZABaAl, 1988, p. 20.

${ }^{21}$ Ibidem, n. ${ }^{\circ} 65$, p. 24.

22 Ibidem, n. ${ }^{\circ} 66$, p. 24

${ }^{23}$ Sagrada Congregación Para el Culto Divino, Conciertos en las iglesias, Roma 5-XI-1987, n. ${ }^{\circ}$ 7. En: Aldazábal, 1988, p. 96.

24 PABLo VI, Sacrosancrum Concilium, op. cit., n. ${ }^{\circ} 116$. 
lengua oficial y universal de la Iglesia: el latín. Así nos lo recuerda el Papa Juan Pablo II: «Merece, ciertamente, especial mencion el canto gregoriano, que por su importancia y valor sigue siendo reconocido, tanto en la práctica cotidiana de la Iglesia como por su magisterio, como canto propio de la liturgia romana y ligado por estrechos vínculos con la lengua latina» ${ }^{25}$. Además, desde sus comienzos «estaría destinado a convertirse en el padre de la moderna música occidental ${ }^{26}$.

Su valoración no ha partido sólo de la Iglesia, sino que es compartida por los grandes genios de nuestra música. Por ejemplo, Mozart exclamaba: «De buena gana daría toda mi gloria por haber tenido la honra de componer el Prefacio de la Misa» ${ }^{27}$, y Gounod afirmaba sobrecogido: «No conozco obra alguna de ningún genio que pueda compararse con la terrible majestad de esos cantos sublimes, que diariamente escuchamos en nuestros templos, en los oficios de difuntos: Dies irae, De profundis. Imposible llegar a tanta altura y a tanto poder de expresión y de impresión $)^{28}$.

Dada su importancia, ha sido continua fuente de inspiración de los músicos de nuestra cultura hasta nuestros dias, de música sacra y aún profana. Por ejemplo, la bella melodía del Dies irae, antigua secuencia de la Misa de Difuntos y actual Himno de las ferias de la última semana del Tiempo Ordinario en la Liturgia de las Horas, aparece en el quinto tiempo de la popular Sinfonia Fantástica (1830) del romántico francés Héctor Berlioz ${ }^{29}$. El siete de junio de este año de 1998 se estrenó en la Catedral de Sevilla el Concierto Sacro Hispalense para órgano y conjunto de metales y timbales, obra encargada por el Cabildo eclesiástico al afamado músico Manuel Castillo; todo él es un diálogo con nuestra tradición musical sacra, y entre los temas que escoge está las melodías de la antífona Ave Maria $\mathrm{y}$ del himno Veni creator, de las más populares del repertorio gregoriano.

Un punto que nos interesa especialmente es que el gregoriano, asimismo, es, con frecuencia, punto de partida para la improvisación del organista, que «se hace necesaria en muchas ocasiones durante las funciones liturgicas $)^{30}$. Muy a menudo los temas que glosan son los textos eucológicos cantados en gregoriano en el curso de la celebración, dotándola así de una unidad y contribuyendo a resaltar por medio de la música el carácter sagrado y litúrgico de ella; así lo expresa un organista: «Amoldado enteramente a la Liturgia, es decir, inspirándose en la magnificencia de los textos litúrgicos y en las líneas gregorianas, que

\footnotetext{
25 Al arzobispo de Colonia Joseph, Cardenal Hoffiner, 25-V-1980. En ALDAZABal, 1988, p. 43.

26 CALDWELL, 1984, p. 14

27 AzCÁRATE, 1951, p. 159.

28 Ibidem.

29 AA. VV., 1993, t. 3, p. 56.

30 ManzárRaga, 1965 , p. 8.
}

Actas del I Congreso de Historia de la Iglesia y el Mundo Hispánico Hispania Sacra, 52 (2000) 
son como la "paráfrasis etérea y moviente de la inmóvil estructura de las catedrales) (Huysmans). En una palabra, cada domingo conviene comentar el oficio divino de la Santa Misa por medio de improvisaciones musicales o de obras que tengan estrecha relación con los textos del día... Las formas musicales que yo empleo - terminó diciendo Tournemire- preferentemente son el preludio, la fuga, el coral y, sobre todo, la forma de las formas: la gran variación betovenianas ${ }^{31}$.

Nosotros vamos a ceñirnos en nuestro estudio a un tema gregoriano: el de la Salve Regina en tono solemne y a una forma musical para órgano netamente española: el tiento, íntimamente relacionada con el hecho de la improvisación, en un músico sevillano -organista, teórico y compositor-, del siglo XVII: Francisco Correa de Arauxo (1584-1654).

\section{La Salve Regina solemNe}

La Salve Regina es una antifona de las llamadas mariales finales, porque se cantan o rezan en el Oficio Divino según el Rito romano al final de las horas canónicas, prescrito hoy sólo en las Completas ${ }^{32}$, última del día, colofón por tanto de toda la liturgia cotidiana ${ }^{33}$. Junto a ella encontramos el Alma Redemptoris Mater, el Ave Regina caelorum, el Regina coeli, y el Sub tuum praesidium. Tradicionalmente se asigna para el Tiempo Ordinario. Es además el canto mariano más popular de la liturgia católica.

En gregoriano tiene dos versiones musicales, una en tono solemne y otra en tono simple. Nos interesa la primera, que es sin duda obra de Adhémar de Monteil, obispo de Puy-en-Vezelay (1087-1098) ${ }^{34}$. Es una melodía grave del modo ${ }^{35} I$ (tónica, re; dominante, la), cuyo cadencioso balanceo evoca los arcos de medio punto del mundo románico. Este modo es solemne y majestuoso ${ }^{36}$, que en sus saltos de 50 hacia las alturas muestra su confianza en la divinidad ${ }^{37}$. Se muestra por lo tanto

\footnotetext{
${ }^{31}$ Ibidem, p. 17. Eran palabras de Carlos Toumemire, organista de Santa Clotilde de París.

32 «Finalmente, se dice una de las antifonas a la Santisima Virgen María. En tiempo pascual será siempre la antifona "Regina caeli"» (PABLo VI, Ordenación general de la Liturgia de las Horas, 2-II$1971, \mathrm{n}^{\circ}{ }^{\circ}$ ).

33 Vid. RAGUER, 1972, p. 166.

34 Predicó la I Cruzada por encargo del Papa Beato Urbano II. Vid. carpetilla de la grabación discográfica de la Abadía de San Pedro de Solesmes: Fiestas de Nuestra Señora, Ediciones Paulinas, Madrid 1984.

${ }_{35}$ "Carácter" o "colorido" que tiene una escala por la colocación de sus tonos y semitonos en relación a la tónica (Tónica, nota en la que comienza la escala)» (HERAs ALONSO, 1995, p. 60).

${ }_{36}$ Cada modo se adecua por su expresividad a los diferentes textos eucológicos. Vid. ibidem, pp. 71 ss.

37 Vid. ibidem, p. 72.
}

Actas del I Congreso de Historia de la Iglesia y el Mundo Hispánico

Hisparia Sacra, 52 (2000) 
muy adecuado para expresar musicalmente los sentimientos graves de súplica ferviente a la Madre del Señor que se vierten poéticamente en esta antífona.

Como nota interesante, el canto mariano más popular en España en lengua vernácula, el Salve Madre ${ }^{38}$, con música de Eduardo Torres Pérez, Maestro de Capilla de la Catedral de Sevilla, presenta el mismo comienzo (la, sol, la, re), aunque con alteración rítmica, que la melodía gregoriana que hemos escogido como representativa a estudiar.

\section{Francisco Correa de arauxo y la Salve Regina solemne}

Nuestro compositor ${ }^{39}$ nació en Sevilla en 1584. Formado musicalmente en esta ciudad, a los quince años obtiene por oposición la plaza de organista titular de la Colegial del Salvador. En 1608 se ordena de presbítero. En 1613 oposita en la Catedral pero no consigue por motivos extramusicales plaza en ella. Tras pasar por varios beneficios, acaba en la Catedral de Segovia hasta su muerte en 1654. Su obra original la conocemos hoy por su Facultad Orgánica, publicada en 1626 en Alcalá de Henares.

En su libro el sistema de escritura utilizado es la cifra arábiga ${ }^{40}$. Estaba dirigido a estudiantes de órgano y fue un libro básico para el estudio de éste en Espaffa ${ }^{41}$. Recoge sesenta y nueve composiciones: sesenta y dos tientos o discursos, tres prosas sobre canto llano, tres glosas de canciones y una diferencia sobre la canción Guárdame las vacas.

De su obra nos interesan los tientos. El tiento es una forma musical instrumental de carácter libre -por tanto derivada de la improvisación-, en la que a partir de un tema inicial, generalmente de canto llano, se van sucediendo las entradas de las restantes voces; a continuación pueden introducirse variaciones sobre este tema, aparecer temas secundarios, reexposiciones $u$ otros recursos de contraste contrapuntístico. Surge en el siglo XVI y está emparentado con el ricercare italiano y el voluntary inglés.

${ }^{38}$ Himno del Congreso Mariano Hispano-Americano de Sevilla de 1929. La letra es el Fr. Restituo del Valle, agustino de El Escorial. Vid.: ViDEs, 1930, pp. 108-116. Su popularidad es reconocida por el Secretariado Nacional de Liturgia al ser incluido con el número 309 en el Cantoral Litúrgico Nacional, 1982, pp. $259 \mathrm{~s}$.

39 Para mayor abundancia de datos biograficos, vid. AYARRA, 1986.

40 Se había implantado tras la publicación del Libro de cifra nueva de Venegas de Hinestrosa en 1557. A cada nota le correspondía un número, y la tesitura venía dada por los caracteres gráficos.

${ }^{41}$ Por ejemplo, Joseph de Torres, organista de la Capilla Real de Madrid en 1702, lo tuvo muy en cuenta como se deduce del ejemplar anotado por su propia mano. Cf. CoRTÉs I MIR, 1992, p. 8.

42 Significativamente las tres últimas piezas de su libro son Prosa del Santissimo Sacramento (n."

Actas del I Congreso de Historia de la Iglesia y el Mundo Hispánico

Hispania Sacra, 52 (2000) 
De los sesenta y dos tientos de Correa, vamos a centrar nuestro estudio en los treinta y cinco primeros, que se incluyen en el primer volumen de la edición de La Facultad Orgánica de 1948. En ellos con frecuencia aparece como tema la incoación de la antifona Salve Regina en tono solemne gregoriana (la, sol, la, re). En unos, como tema principal; en otros, como secundario. No olvidemos su dedicación a la Liturgia y lo cotidiano de la interpretación de esta melodía para él, que acompañaba el Oficio Divino en sus sucesivos beneficios. A esto añadamos el intenso marianismo de Ia Iglesia hispalense en la que se formó, aumentado si cabe por el ambiente contrarreformista ${ }^{42}$.

Se pueden agrupar los ejemplos, por el tratamiento del tema, en tres apartados:

a) Respeta el estado original: en el Tiento I, compás 125, en la voz de bajo; Tiento III, comp. 119 s. (alto) y comp. 130-3 (bajo); Tiento $I$, comp. 157 (tenor) ${ }^{43}$ y comp. 54-6 (tiple); Tiento VIII, comp. 90-3 (bajo) ${ }^{29}$; Tiento $L X$, comp. 159 s. (bajo); Tiento $X V I$, comp. 146-9 (tenor); Tiento $X I X$, comp. 34-6 (bajo); Tiento XXIV, comp. 1-3 (alto), 4-6 (tenor), 7-9 (tiple), 10-2 (bajo), 17-9 (bajo) y 36-40 (bajo); Tiento $X X V$, comp. 34-6 (bajo); Tiento $X X V I$, comp. 1-3 (tenor de forma tonal), comp. 3-5 (bajo), comp. 6-8 (alto), comp. 12-4 (tiple de forma tonal), comp. 26-8 (bajo), comp. 30-2 (tiple), comp. 57-60 (bajo), comp. 97-9 (alto), comp. 102-4 (bajo), comp. 105-8 (tiple de modo tonal) y comp. 109-12 (tenor de forma tonal), y Tiento $X X X$, comp. 49-51 (tenor).

b) Tema con modificación rítmica: Tiento $I$, comp. 27-30 (tiple), $77 \mathrm{~s}$. (tiple), comp. 79 s. (bajo) y comp. 80 s. (alto); Tiento II, comp. 72-4 (tenor); Tiento VII, comp. 53-5 (tiple); Tiento XII, comp. 49 (tenor); Tiento XIV , comp. 81 (alto) ${ }^{29}$; Tiento XVIII, comp. 71-3 (bajo), comp. 74-6 (tiple), comp. 77-9 (tenor) y comp. 92-4 (alto), y Tiento XXX, comp. 29 (bajo), comp. 30 s. (bajo) y 52-4 (tiple).

c) Tema explicitado por la aplicación del quiebro44: Tiento XIV, comp. $1 \mathrm{~s}$. (tiple), comp. 10 s. (tenor) y comp. 29 (bajo); Tiento $X X V$, comp. $1 \mathrm{~s}$.

LXVII), Canto Llano de la Inmaculada Concepción de la Virgen Maria (n. ${ }^{\circ}$ LXVIII) y Tres Glosas sobre el Canto Llano de la Inmaculada Concepción ( $\left({ }^{\circ}\right.$ LXIX): Eucaristía e Inmaculada, las dos grandes amores de la religiosidad sevillana. En la misma línea va el colofon: «Alabado Sea El Santíssimo Sacramento y la Inmaculada Concepción de la Virgen Maria Nuestra Señora Concebida sin mancha de pecado original.»

${ }^{43}$ La voz resuelve la última nota en octava alta por razones técnicas.

4 "Quiebro es [...] una baxada y subida hecha con velocidad en dos o tres signos) (CORREA, La Facultad Orgánica, fol. 15. En: KASTNER, 1948, p. 54). En la escritura sólo aparece indicada la primera de las notas. Nos referimos al quiebro sencillo: «Se puede ( $y$ aun se deve) usar en todo principio de verso, o obra pequefia más propiamente: y en medio de ella, en todos los semibreves, y mínimas en que 
(alto), comp. 3 s. (tenor), comp. 6 s. (bajo), comp. 12 s. (tiple), comp. 22 s. (tenor), comp. $27 \mathrm{~s}$. (alto) y comp. 31 s. (tiple), y Tiento XXVII, comp. $1 \mathrm{~s}$. (alto), comp. $4 \mathrm{~s}$. (tenor), comp. $10 \mathrm{~s}$. (tiple), comp. $17 \mathrm{~s}$. (tiple) y comp. 33 s. (tiple).

En el XXIV Tiento pequeño y fácil de séptimo tono ${ }^{45}$ y en XXVI Segundo Tiento de medio registro de tiple de séptimo tono ${ }^{46}$ se presenta como tema principal, por lo que los consideramos los más destacados. El primero de los enurciados podemos considerarlo el más importante porque está concebido a modo de compendio de su obra ${ }^{47}$ y por ser en el que más trata el tema de la Salve. Éste es presentado por la voz de contralto, a la que le seguirán escolásticamente las demás (tenor, tiple y bajo respectivamente); después de la última entrada, el bajo repite el tema a una cuarta inferior en el comp. 17; más adelante, en el comp. 27, se introduce como tema secundario una variación melódica del de la $S a l v e^{48}$, y reaparece el tema en el comp. 36 con notas largas en el bajo, lo que lo reviste de gran solemnidad al ser el sostén armónico de la pieza.

En el $X X V I$ aparece el tema tratado de forma tonal en la voz de tenor y tiple, mientras que bajo y contralto lo hacen modalmente, como corresponde a la melodía original. Se desarrolla dicho tema de idéntica forma que al principio del Tiento XXIV. Se ha de destacar que cuando el tiple se presenta, el tenor lo acompaffa en ese comp. 12 en forma de canon y resuelve el tema irregularmente en el comp. 15. El tema gana en brillantez expositiva al ser presentado de forma solista por la voz de tiple ${ }^{49}$.

\section{CONCLUSIONES}

1) La música sagrada es inherente a todo hecho religioso, incluida la Liturgia cristiana, celebración gozosa de la Pascua del Señor.

\footnotetext{
la mano (qualquiera que sea), se hallare desocupada de glosa: y quando se tafiere el compás ligero, o a compás mayory (ibidem, fol. 16. En: ibidem, p. 55).

${ }^{45}$ KASTNER, 1948, t. I, p. 138.

46 Ibidem, t. I, p. 147.

47 Aparecen los tres esquemas de tiento que utiliza en su producción: empieza con un tiento de lleno (en el que todas las voces tienen la misma importancia), le sigue el llamado de baxón (el bajo actúa como solista) y continúa con el de tiple (la voz de tiple es la protagonista). Combina, asimismo, los ritmos binario y ternario (ayrecillo).

${ }^{4}$ Los tientos de Correa se caracterizan por su politematicidad, por lo que es poco común que se relacionen temas principales y secundarios.

${ }^{49} \mathrm{El}$ tiento de medio registro estaba pensado para órgano de teclado partido, en el que existe la posibilidad de diferenciar dos planos sonoros, pudiendo destacar los graves o los agudos.
}

Actas del I Congreso de Historia de la Iglesia y el Mundo Hispánico Hispania Sacra, 52 (2000) 
2) El Gregoriano se presenta como la música sacra por excelencia de la civilización occidental y en el principio de su desarrollo, por lo que influye decisivamente en la tradición posterior, sobre todo en la música sagrada, como motivo de inspiración y modelo.

3) Ejemplo de ello es la influencia del popular tema gregoriano de la Salve Regina en tono solemne, interpretado diariamente en el Oficio de Completas y en celebraciones marianas.

4) Correa de Arauxo, organista sevillano del XVII, lo toma insistentemente como tema principal y secundario de sus tientos. Esta predilección puede deberse a lo cotidiano de su interpretación y a un marcado marianismo, que es nota común en la Iglesia hispalense en la que se formó.

\section{BIBLIOGRAFIA}

AldazÁbal, J. (preparado por), Canto y música, Dossier 27, Centre de Pastoral Litúrgica, Barcelona 1985.

ALDAZÁBAL, J. (preparado por), La música en la Liturgia. Documentos, Dossier 38, Centre de Pastoral Litúrgica, Barcelona, 1988.

AA. VV.: Concilio Vaticano II... Tomo I. Comentarios a la constitución sobre la sagrada liturgia, BAC, Madrid, 1965.

AA. VV.: Los dioses de la música 93, Planeta, Barcelona, 1993.

AA. VV.: Por qué cantar en la Liturgia, Cuaderno Phase 28, Centre de Pastoral Litúrgica, Barcelona, 1991.

AYARRA JARNÉ, J. E.: Francisco Correa de Arauxo, organista sevillano del siglo XVII, Diputación Provincial, Sevilla, 1986.

AZCARATE, A.: La flor de la liturgia, Buenos Aires (Argentina), 1951.

CAldWell, J.: La música medieval, Alianza Editorial, Madrid, 1984.

CORTÈs Mir, F.: Francisco Correa de Arauxo. «Libro de Tientos y Discursos de Música Práctica, y Theórica de Órgano» (Carpetilla de la grabación en disco compacto), Patronat de la Música de Badalona, 1992, pp. 6-9.

FERNÁNDEZ DE LA CUESTA, I.: Historia de la música española: 1. Desde los orígenes hasta el "ars nova», Alianza, Madrid, 1983.

GarRido BonaN̂o, M.: "La música sagrada», en: Concilio Vaticano $I I$, t. I, BAC, Madrid, 1965, pp. 545-581.

GoMA TOMÁs, I.: El valor educativo de la Liturgia Católica, Casulleras, Barcelona, 1945.

Heras Alonso, P.: El canto gregoriano. Guia breve para su comprensión, P. S. Editorial, Madrid, 1995.

Actas del I Congreso de Historia de la Iglesia y el Mundo Hispánico

Hispania Sacra, 52 (2000) 
Kastner, M. S.: Libro de Tientos y Discursos de Música Práctica y Theórica de Óngano intitulado Facultad Orgánica. Alcalá 1626, Francisco Correa de Aratoxo. Edición y transcripción de CSIC, Barcelona, 1948.

MANZARRAGA, T. de: El órgano tradicional litúrgico, Coculsa, Madrid, 1965.

RAGUER, H. M.: La nueva Liturgia de las Horas, Editorial Vizcaína, Bilbao, 1972.

SeCretariado Nacional de Liturgia: Cantoral Litúrgico Nacional, Coeditores Litúrgicos, Barcelona, 1982.

VIDES, J. de: Crónica oficial del Congreso Mariano Hispano-Americano de Sevilla... celebrado del 15 al 21 de mayo de 1929, Madrid, 1930.

Actas del I Congreso de Historia de la Iglesia y el Mundo Hispánico

Hispania Sacra, $52(2000)$ 